\title{
IMPLEMENTASI METODE PIXEL VALUE DIFFERENCING UNTUK PENYEMBUNYIAN PESAN PADA CITRA DIGITAL
}

\author{
Ricky Andri, Rivalri Kristianto Hondro, Kennedi Tampubolon
}

\author{
Program Studi Teknik Informatika STMIK Budi Darma, Medan, Indonesia \\ Email : rickypriker@gmail.com
}

\begin{abstract}
Abstrak
Perkembangan teknologi informasi yang sangat cepat, menimbulkan banyak celah keamanan yang dapat disalahgunakan oleh orang-orang yang tidak bertanggungjawab sehingga dapat merugikan pihak-pihak tertentu. Citra digital dipilih sebagai wadah untuk menyisipkan pesan karena citra digital memiliki ukuran yang cukup untuk menampung pesan tersebut dan citra digital sudah sering digunakan dalam pertukaran informasi sehingga tidak mengundang kecurigaan dari pihak yang tidak bertanggung jawab. Informasi yang akan dikirim disembunyikan dalam citra digital, kemudian citra digital tersebut dikirim seperti data biasa, sehingga pihak ketiga tidak curiga bahwa di dalamnya terdapat informasi rahasia. Informasi yang disembunyikan dalam citra digital tersebut dapat diekstrak kembali oleh penerima pesan. Pixel Value Differencing (PVD) bekerja pada sepasang nilai piksel yang bertetanggaan (adjacent piksel). Kelebihan pada Metode Pixel Value Differencing (PVD) ini adalah kapasitas citra yang dihasilkan untuk menyisipkan pesan bisa lebih kecil dari ukuran aslinya, waktu proses pada metode ini cukup cepat, setelah disisipi pesan, kualitas citra mempunyai kualitas yang baik. Namun metode ini juga masih mempunyai kekurangan, karena tidak tahan terhadap manipulasi.
\end{abstract}

Kata Kunci : Steganografi, Citra Digital, Pixel Value Differencing

\begin{abstract}
The development of information technology is very fast, causing a lot of security holes that can be misused by people who are not responsible so that it can harm certain parties. Digital images are chosen as a container for inserting messages because digital images have sufficient size to hold the message and digital images are often used in information exchange so as not to invite suspicion from irresponsible parties. The information to be sent is hidden in a digital image, then the digital image is sent as normal data, so that third parties do not suspect that there is confidential information inside. Information that is hidden in the digital image can be extracted again by the recipient of the message. Pixel Value Differencing (PVD) works on a pair of adjacent pixel values (adjacent pixels). The advantage of the Pixel Value Differencing (PVD) method is that the capacity of the image generated to insert a message can be smaller than its original size, the processing time of this method is quite fast, after the message is inserted, the image quality has good quality. But this method also has disadvantages, because it is not resistant to manipulation.
\end{abstract}

Keywords: Steganography, Digital Image, Pixel Value Differencing

\section{PENDAHULUAN}

Citra digital merupakan salah satu bentuk data digital yang saat ini banyak dipakai dalam pertukaran informasi dalam bentuk visual. Perkembangan teknologi informasi yang sangat cepat, menimbulkan banyak celah keamanan yang dapat disalahgunakan oleh orang-orang yang tidak bertanggungjawab sehingga dapat merugikan pihak-pihak tertentu. Dibutuhkan langkah preventif untuk menyampaikan informasi ataupun pesan yang bersifat pribadi.

Pengamanan pesan tersebut dapat juga menggunakan teknik kriptografi, namun teknik ini tidak menjamin keamanan pesan secara maksimal, hal ini dikarenakan banyaknya kriptanalis yang telah berhasil memecahkan beberapa algoritma yang ada dalam kriptografi dan perkembangan komputer dengan tingkat komputasi yang cepat sehingga dapat digunakan untuk menebak kunci kriptografi dalam waktu yang cepat. Pesan yang disisipkan ialah pesan rahasia. Pengiriman pesan rahasia juga dapat dilakukan dengan melakukan penyisipan pesan ke dalam sebuah media digital, salah satu media yang dapat digunakan untuk penyisipan pesan adalah citra digital. Citra digital dipilih sebagai wadah untuk menyisipkan pesan karena citra digital memiliki ukuran yang cukup untuk menampung pesan tersebut dan citra digital sudah sering digunakan dalam pertukaran informasi sehingga tidak mengundang kecurigaan dari pihak yang tidak bertanggung jawab. Informasi yang akan dikirim disembunyikan dalam citra digital, kemudian citra digital tersebut dikirim seperti data biasa, sehingga pihak ketiga tidak curiga bahwa di dalamnya terdapat informasi rahasia. Informasi yang disembunyikan dalam citra digital tersebut dapat diekstrak kembali oleh penerima pesan. Informasi tersebut juga harus sama dengan informasi sebelum disisipkan dalam citra digital, meskipun citra digital tersebut telah mengalami proses manipulasi, seperti pengeditan, pemotongan atau kompresi. Steganografi sebagai suatu seni penyembunyian pesan ke dalam pesan lainnya yang telah ada sejak sebelum masehi dan kini seiring dengan kemajuan teknologi jaringan serta perkembangan dari teknologi digital, steganografi banyak dimanfaatkan untuk mengirim pesan melalui jaringan Internet tanpa diketahui orang lain dengan menggunakan media digital berupa file gambar. Pesan juga dapat dikirim melalui aplikasi layanan pesan instan. Aplikasi layanan pesan instan saat ini sudah sangat maju, tidak hanya mengirim pesan teks saja, aktivitas chatting sekarang ini juga bisa mengirimkan emoticon, pesan suara, bahkan video. Singkatnya, aplikasi layanan pesan instan adalah bentuk komunikasi yang paling efektif dan efisien saat ini. 
Pixel Value Differencing (PVD) bekerja pada sepasang nilai piksel yang bertetanggaan (adjacent piksel). Proses penyisipan informasi dilakukan dengan memodifikasi selisih nilai piksel (Pixel Value Differencing) sesuai dengan nilai bit pesan dan tabel kuantisasi selisih nilai keabuan. Kuantisasi selisih nilai keabuan digunakan untuk menentukan jumlah bit yang akan disisipkan pada selisih nilai tertentu. Kelebihan pada Metode Pixel Value Differencing (PVD) ini adalah kapasitas citra yang dihasilkan untuk menyisipkan pesan bisa lebih kecil dari ukuran aslinya, waktu proses pada metode ini cukup cepat, setelah disisipi pesan, kualitas citra mempunyai kualitas yang baik[1].

\section{TEORITIS}

\subsection{Steganografi}

Steganografi adalah seni dan ilmu menulis pesan tersembunyi atau menyembunyikan pesan dengan suatu cara sehingga selain si pengirim dan si penerima, tidak ada seorangpun yang mengetahui atau menyadari bahwa ada suatu pesan rahasia. Sebaliknya, kriptografi menyamarkan arti dari suatu pesan, tapi tidak menyembunyikan bahwa ada suatu pesan[2].

\subsection{Citra Digital}

Secara umum, pengolahan citra digital menunjuk pada pemrosesan gambar 2 dimensi menggunakan komputer. Dalam konteks yang lebih luas, pengolahan citra mengacu pada pemrosesan setiap data 2 dimensi. Citra digital merupakan sebuah larik (array) yang berisi nilai-nilai real maupun komplek yang direpresentasikan dengan deretan bit tertentu[3].

\subsection{Metode Pixel Value Differencing (PVD)}

Pixel Value Differencing (PVD) bekerja pada sepasang nilai piksel yang bertetanggaan (adjacent pixel). Proses penyisipan informasi dilakukan dengan memodifikasi selisih nilai piksel (pixel value difference) sesuai dengan nilai bit pesan dan tabel kuantisasi selisih nilai keabuan. Kuantisasi selisih nilai keabuan digunakan untuk menentukan jumlah bit yang akan disisipkan pada selisih nilai tertentu[4].

Salah satu rentang nilai keabuan yang diusulkan oleh Wu dan Tsai adalah [8 8163264 128] :

Tabel 1. Rentang Nilai Keabuan

\begin{tabular}{cccc}
\hline Kuantisasi ke-k & Batas Bawah - Batas Atas $l_{\mathrm{k}}-\mathrm{u}_{\mathrm{k}}$ & Rentang Nilai & Jumlah Bit $\mathrm{n}$ \\
\hline 1 & $0-7$ & 8 & 3 \\
2 & $8-15$ & 8 & 3 \\
3 & $16-31$ & 16 & 4 \\
4 & $32-63$ & 32 & 5 \\
5 & $64-127$ & 64 & 6 \\
6 & $128-255$ & 128 & 7 \\
\hline
\end{tabular}

Proses penyisipan pesan pada metode PVD :

1. Ubah pesan menjadi bilangan 8 biner

2. Hitung Selisih 2 piksel bertetangga $\left(\mathbf{g}_{\mathbf{i}}, \mathbf{g}_{\mathbf{i}+\mathbf{1}}\right)$ :

$\mathrm{d}_{\mathrm{i}}=\mathrm{g}_{\mathrm{i}+1}-\mathrm{g}_{\mathrm{i}}$

3. Tentukan batas bawah $\left(\mathbf{l}_{\mathbf{k}}\right)$ dan jumlah $\mathbf{n}$ bit, dengan cara :

$\mathrm{l}_{\mathrm{k}} \leq \mathrm{d}_{\mathrm{i}}<\mathrm{l}_{\mathrm{k}+1}$

4. Ambil pesan sebanyak $\mathbf{n}$ bit, kemudian ubah menjadi desimal (d)

5. Hitung selisih nilai yang baru $:_{\mathrm{k}}$

$\mathrm{d}^{\prime}=\left\{\begin{aligned} \boldsymbol{l}_{\boldsymbol{k}}+b, & d \geq 0 \\ -\left(\boldsymbol{l}_{\boldsymbol{k}}+b\right), & d<0\end{aligned}\right.$

6. Hitung: $\mathbf{m}=\mathbf{d}$ ' $-\mathbf{d}$

7. Hitung nilai piksel baru :

$$
\mathrm{f}\left(\mathrm{g}^{\prime}{ }_{i, g{ }^{+}+1}\right)= \begin{cases}\left(g_{i}-\left\lceil\frac{m}{2}\right\rfloor, g_{i+1}+\left\lceil\frac{m}{2}\right\rceil\right), & m=\text { ganjil } \\ \left(g_{i}-\left\lfloor\frac{m}{2}\right\rfloor, g_{i+1}+\left\lfloor\frac{m}{2}\right\rfloor\right), & m=\text { genap }\end{cases}
$$

Proses ekstraksi pesan dari citra stego menggunakan metode Pixel Value differencing (PVD) dimulai dengan mengurutkan semua piksel pada gambar yang telah disisipkan pesan, sesuai cara pengambilan pesannya. Kemudian dihitung selisih nilai difference value baru $\left(d_{i}\right)$. Berdasarkan informasi tersebut dapat diketahui seberapa panjang data rahasia yang disisipkan pada kedua pixel, sehingga pesan rahasia yang telah disisipkan didapatkan kembali. Proses algoritma Pixel Valuedifferencing (PVD) untuk ekstraksi pesan dapat dijelaskan secara singkat sebagai berikut[4] :

1. Hitunglah selisih 2 piksel bertetangga $\left(\mathbf{g}_{\mathbf{i}}, \mathbf{g}_{\mathbf{i + 1}}\right)$

$$
d_{i}=g_{i+1}-g_{i}
$$


2. Tentukan batas bawah $\left(l_{k}\right)$ dan jumlah bit $\mathbf{n}$, dengan cara :

$1_{\mathrm{k}} \leq \mathrm{d}_{\mathrm{i}}<\mathrm{l}_{\mathrm{k}+1}$

3. Hitung $: b=|d|-l_{k}$

4. Ubah $\mathbf{b}$ (desimal) menjadi biner $\mathbf{n}$ bit

5. Ambil Pesan $=\mathbf{n}$ bit

\section{ANALISA DAN PEMBAHASAN}

\subsection{Analisa Masalah}

Permasalahan yang berkaitan dengan Steganografi untuk penyisipan pesan yaitu pada penyisipan pesan pada teks, gambar, suara dan video. Adapun penyisipan pada pesan teks berformat (pdf dan doc) pada file gambar berformat (jpg, png, bmp dan gift), pada file suara berformat (mp3, wav dan wma), serta pada file video berformat 3gp. Untuk keamanan pesan, Steganografi memiliki tiga cara kerja yaitu hidden text, algoritma penyisipan dan algoritma pendeteksian. Sesuai dengan tujuan Steganografi itu sendiri yaitu menyembunyikan isi pesan, maka dibutuhkan sebuah teknik steganografi penyisipan pesan.

Tujuan pembuatan sistem ini adalah untuk menyembunyikan pesan pada citra digital menggunakan metode Pixel Value Differencing pada aplikasi matlab

1. Proses penyembunyian pesan teks kedalam citra digital :

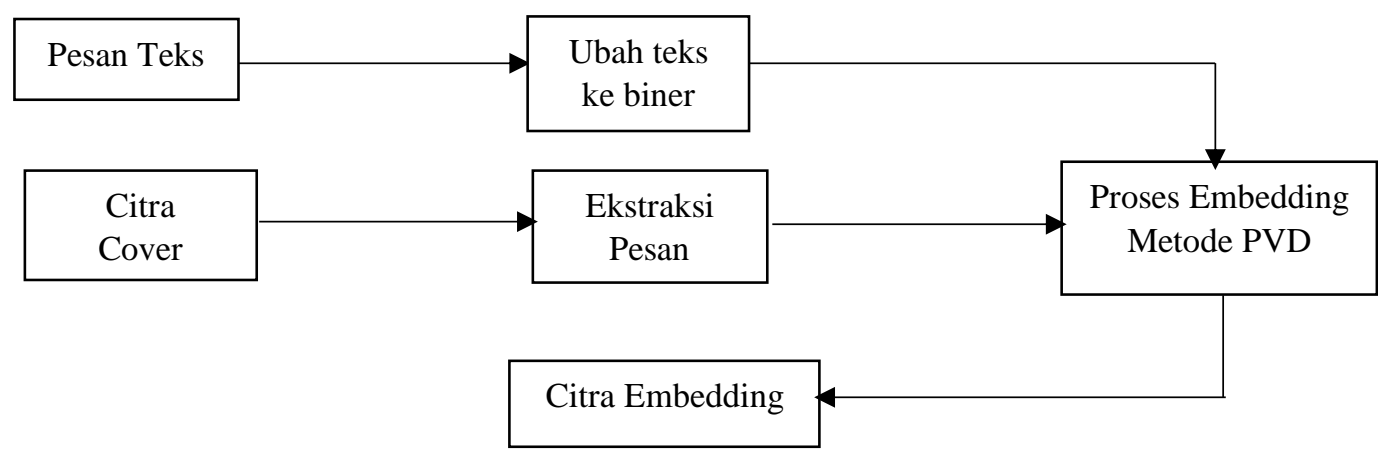

Gambar 1. Proses Penyisipan Pesan Kedalam Citra Digital

a. Pesan teks diubah ke bilangan biner menggunakan tabel ASCII.

b. Citra penampung dibaca nilai piksel menggunakan aplikasi matlab, dilakukan proses penyisipan menggunakan PVD

c. Dan hasilnya berupa Stego image

2. Proses ekstraksi pesan dari citra cover.

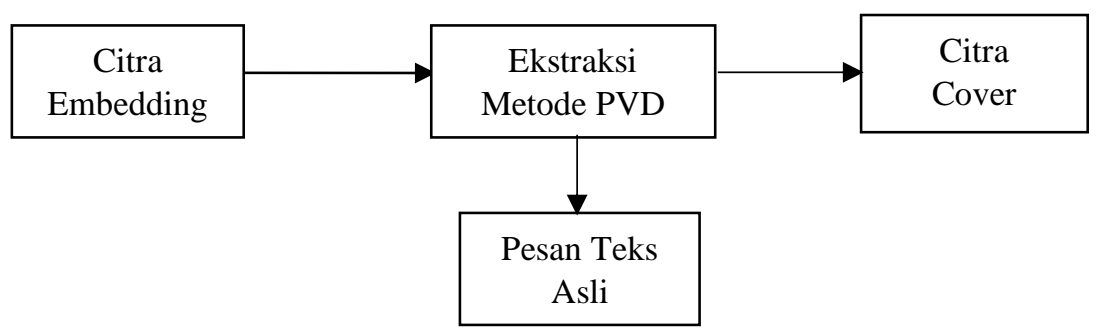

Gambar 2. Proses Ekstraksi Pesan Dari Citra Cover

Citra embedding di ekstraksi menggunakan metode PVD sehingga menghasikan citra cover dan menghasilkan pesan teks yang asli.

\subsection{Analisa Metode Pixel Value Differencing Dalam Penyisipan Pesan}

Penyisipan pesan dilakukan dengan mengubah pesan menjadi bentuk biner dan disisipkan kedalam file citra digital dengan menggunakan metode PVD, sebelum dilakukan penyisipan maka file citra digital harus diubah menjadi bentuk desimal. File citra digital yang digunakan adalah citra.jpg 


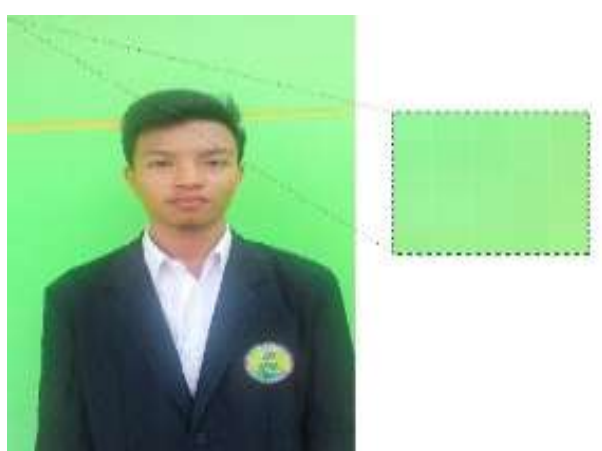

Gambar 3. File Sampel Citra digital

Pesan yang akan disisipkan adalah kata RICK yang akan dirubah menjadi bentuk biner. Wadah Penampung 5 x 5 piksel

1. Merubah pesan menjadi biner dari file gambar menjadi desimal
Pesan
: RICK
File citra

: citra.jpg

Tabel 1. Tabel Biner

Sehingga biner dari pesan menjadi :

\begin{tabular}{lrc}
\hline Karakter & Biner & Desimal \\
\hline $\mathbf{R}$ & 01010010 & 82 \\
$\mathbf{I}$ & 01001001 & 73 \\
$\mathbf{C}$ & 01000011 & 67 \\
$\mathbf{K}$ & 01001011 & 75 \\
\hline
\end{tabular}
01010010010010010100001101001011

2. Membaca citra dalam matlab.

img = imread('C: citra.jpg');

img = imcrop(img, [1,1,4,4]);

$\mathrm{r}=\operatorname{img}(:,:, 1)$;

$\mathrm{g}=\operatorname{img}(:,:, 2)$;

$\mathrm{b}=\operatorname{img}(:,:, 3)$;

Nilai Piksel Kanal R dengan Ukuran 5 x 5

\begin{tabular}{|r|r|r|r|r|}
\hline 150 & 149 & 150 & 156 & 158 \\
\hline 145 & 146 & 148 & 155 & 160 \\
\hline 153 & 153 & 153 & 156 & 160 \\
\hline 155 & 155 & 156 & 156 & 163 \\
\hline 155 & 157 & 158 & 158 & 164 \\
\hline
\end{tabular}

Nilai Piksel Kanal G dengan Ukuran 5 x 5

\begin{tabular}{|l|l|l|l|l|}
\hline 246 & 243 & 243 & 242 & 239 \\
\hline 244 & 242 & 242 & 242 & 240 \\
\hline 243 & 244 & 242 & 240 & 240 \\
\hline 244 & 244 & 243 & 240 & 240 \\
\hline 240 & 242 & 242 & 240 & 242 \\
\hline
\end{tabular}

Nilai Piksel Kanal B dengan Ukuran 5 x 5

\begin{tabular}{|l|l|l|l|l|}
\hline 157 & 155 & 152 & 151 & 144 \\
\hline 153 & 152 & 148 & 148 & 145 \\
\hline 153 & 151 & 148 & 146 & 143 \\
\hline 154 & 154 & 149 & 146 & 144 \\
\hline 146 & 148 & 144 & 142 & 143 \\
\hline
\end{tabular}


Tabel 2. Rentang Nilai Keabuan

\begin{tabular}{cccc}
\hline Kuantisasi ke-k & Batas Bawah - Batas Atas $1_{\mathrm{k}}-\mathrm{u}_{\mathrm{k}}$ & Rentang Nilai & Jumlah Bit $\mathrm{n}$ \\
\hline 1 & $0-7$ & 8 & 3 \\
2 & $8-15$ & 8 & 3 \\
3 & $16-31$ & 16 & 4 \\
4 & $32-63$ & 32 & 5 \\
5 & $64-127$ & 64 & 6 \\
6 & $128-255$ & 128 & 7
\end{tabular}

1. Proses penyisipan pesan ke dalam file citra digital.

a. Jika hasil $\mathrm{d}=$ minus, maka penetapan nilai keabuan tetap dianggap positif.

b. Jika $\mathrm{m}=$ ganjil, maka nilai batas atas diambil dari nilai yang terbesar, batas bawah diambil dari nilai terkecil.

c. Jika $\mathrm{m}=$ genap, maka nilai batas atas dan batas bawah tetap sama.

d. Pesan

$$
=01010010
$$

e. $d$

$$
=149-150=-1
$$

f. $0 \leq|\mathrm{d}| \leq 7, \mathbf{l}_{\mathbf{k}}=8, \mathbf{n}=3$

g. ambil sebanyak 3 bit, b

$=010=2$

h. $\mathrm{d} \leq 0$, maka selisih baru : d

$$
=-\mathbf{l}_{\mathbf{k}}+\mathbf{b}=-(8+2)=10
$$

i. $\mathbf{m}=\mathbf{d}$ ' $-\mathbf{d}$

$$
=-10-(-1)=-9
$$

j. karena m ganjil, maka

$$
\mathrm{f}\left(\mathrm{g}^{\prime}, \mathrm{g}{ }_{\mathrm{i}+1}\right)=\left(150-\left\lceil\frac{-9}{2}\right\rceil, 149+\left\lfloor\frac{-9}{2}\right\rfloor\right) \quad=150-(-5), 149+(-4)=155,145
$$

\begin{tabular}{|l|l|l|l|l|}
\hline 150 & 149 & 150 & 156 & 158 \\
\hline 145 & 146 & 148 & 155 & 160 \\
\hline 153 & 153 & 153 & 156 & 160 \\
\hline 155 & 155 & 156 & 156 & 163 \\
\hline 155 & 157 & 158 & 158 & 164 \\
\hline
\end{tabular}

\begin{tabular}{|l|l|l|l|l|}
\hline 155 & 145 & 150 & 156 & 158 \\
\hline 145 & 146 & 148 & 155 & 160 \\
\hline 153 & 153 & 153 & 156 & 160 \\
\hline 155 & 155 & 156 & 156 & 163 \\
\hline 155 & 157 & 158 & 158 & 164 \\
\hline
\end{tabular}

\section{IMPLEMENTASI}

Algoritma merupakan urutan langkah-langkah untuk menyelesaikan suatu masalah. Dalam penelitian ini algoritma Pixel Value Differenching akan disisipkan dalam bentuk pseudocode sebagai berikut :

1. Pseudocode Embedding Pixel Value Differenching

Input: Pesan, Citra Penampung

Output : : Stegoimage

Proses : for $\mathrm{i}=1: 2$ :panjang_stego

$\mathrm{d}=\operatorname{stego}(\mathrm{i}+1)-\operatorname{stego}(\mathrm{i})$;

if $0<=\mathrm{d}<=7 ; \mathrm{Lk}=0 ; \mathrm{n}=3$; end

if $8<=\mathrm{d}<=15 ; \mathrm{Lk}=8 ; \mathrm{n}=3$; end

if $16<=\mathrm{d}<=31 ; \mathrm{Lk}=16 ; \mathrm{n}=4$; end

if $32<=\mathrm{d}<=63 ; \mathrm{Lk}=32 ; \mathrm{n}=5$; end

if $64<=\mathrm{d}<=127 ; \mathrm{Lk}=64 ; \mathrm{n}=7$; end

if $128<=\mathrm{d}<=255 ; \mathrm{Lk}=128$; $\mathrm{n}=7$; end

if $\mathrm{n}>$ length(bit_pesan) 
$\mathrm{n}=$ length(bit_pesan);

break

end

ambil_bit_pesan=bit_pesan(1:n);

bit_pesan=bit_pesan( $\mathrm{n}+1$ :end);

b=bin2dec(ambil_bit_pesan);

if $\mathrm{d}>=0 ; \mathrm{dl}=\mathrm{Lk}+\mathrm{b}$; else $\mathrm{dl}=-(\mathrm{Lk}+\mathrm{b})$; end

$\mathrm{m}=\mathrm{dl}-\mathrm{d} ;$ bawah=floor $(\mathrm{m} / 2)$; atas=ceil $(\mathrm{m} / 2)$;

if $\bmod (\mathrm{m}, 2)==1, \operatorname{stego}(\mathrm{i})=\operatorname{stego}(\mathrm{i})$-atas;

stego $(\mathrm{i}+1)=$ stego $(\mathrm{i}+1)+$ bawah; end

if $\bmod (\mathrm{m}, 2)==0$, stego(i)=stego(i)-bawah;

stego $(i+1)=\operatorname{stego}(i+1)+$ atas; end

end

stego=reshape(stego, [baris kolom]); \%cerita baris dijadikan matrik

figure,

subplot(2,1,1),imshow (citra), title('Citra Asli');

subplot(2,1,2),imshow (citra), title('Citra Stego');

imwrite(stego,'d:'coba.jpg');

2. Pseudocode Ekstraksi Pixel Value Differenching

Input: Stegoimage

Output : Pesan, Citra Penampung

Proses : bit_pesan=[];

ambil_bit_pesan=[];

for $\mathrm{i}=1: 2$ : panjang_stego

if length(bit_pesan)==panjang_bit_pesan, break, end

$\mathrm{d}=$ stego(i+1)-stego(i);

if $0<=\mathrm{d}<=7 ; \mathrm{Lk}=0 ; \mathrm{n}=3$; end

if $8<=\mathrm{d}<=15 ; \mathrm{Lk}=8 ; \mathrm{n}=3$; end

if $16<=\mathrm{d}<=31 ; \mathrm{Lk}=16 ; \mathrm{n}=4$; end

if $32<=\mathrm{d}<=63 ; \mathrm{Lk}=32 ; \mathrm{n}=5$; end

if $64<=\mathrm{d}<=127 ; \mathrm{Lk}=64 ; \mathrm{n}=7$; end

if $128<=\mathrm{d}<=255 ; \mathrm{Lk}=128 ; \mathrm{n}=7$; end

$\mathrm{b}=\mathrm{abs}(\mathrm{d}-\mathrm{Lk})$;

ubah_b = dec2bin(b);

bit_pesan $=$ [bit_pesan ubah_b];

end

pesan2=[];

for $\mathrm{i}=1: 8$ : panjang_bit_pesan

$\mathrm{a}=$ char(bin2dec(bit_pesan(1:8)));

pesan $2=[$ Pesan a $]$;

end

pesan2=pesan2(1:end-1)

Proses pengujian dengan menggunakan aplikasi Matrix Laboratory (MATLAB) pada pengujian implementasi metode Pixel Value Differencing (PVD) untuk melakukan penyisipan pesan teks pada citra digital.

Tabel 3. Hasil Pengujian

\begin{tabular}{cccc}
\hline File Asli citra & Stego image & Manipulasi & Hasil \\
Pesan Output
\end{tabular}



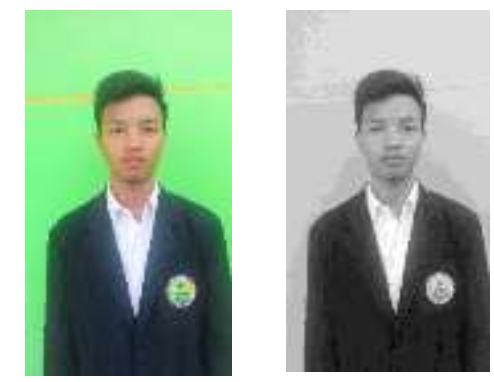

Dirubah ke rotasi kanan dan

RICK

Pesan tidak kembali di tingkatkan kontrasnya menjadi $45 \%$

\section{KESIMPULAN}

Berdasarkan penelitian yang telah dilakukan, dapat diambil beberapa kesimpulan sebagai berikut :

1. Teknik Pixel Value Differencing (PVD) dapat digunakan untuk menyembunyikan pesan teks kedalam citra digital, namun ketika citra digital dimanipulasi, pesan yang di ekstraksi tidak dapat kembali.

2. Penerapan metode Pixel Value Differencing (PVD) berhasil menyisipkan pesan teks pada citra digital dengan melihat perbedaan atau selisih antara dua piksel yang bertetangga.

3. Perubahan yang terjadi pada citra digital yang telah disisipkan pesan teks tidak terlalu signifikan, sehingga tidak menimbulkan kecurigaan.

\section{REFERENCES}

[1] M. Z. Siambaton, "Kombinasi Algoritma Pixel Value Differencing Dengan Algoritma Caesar Cipher Pada Proses Steganografi," CESSJournal Comput. Eng. Syst. Sci., vol. 1, no. 2, pp. 19-25, 2016.

[2] Irfan, "Penyembunyian Informasi ( steganography ) Gambar Menggunakan Metode LSB ( Least Significant Bit )," Rekayasa Teknol., vol. 5, no. 1, pp. 1-6, 2013.

[3] D. Putra, Pengolahan Citra. Yogyakarta: Andi, 2010.

[4] M. Pulung Nurtantio Andono, T. Sutojo, Pengolahan Citra Digital. Yogyakarta: Andi, 2017. 